A publication of the Muma College of Business | University of South Florida

\begin{tabular}{lll}
\hline Volume 5 & Number 4 & 1 JUNE 2020 \\
\hline
\end{tabular}

SCOT'T BREITENGROSS, SCOT'T CAMPBELL, ROGER CAPOTE, LEIGH COWAN AND ADILAH EVERETT-LONG

\title{
SOCIAL SUICIDE: SHOW ME THE MONEY ${ }^{1}$
}

"We stood to receive the greatest financial contribution ever offered to our organization. In an instant, it was gone." -Roger Capote

Roger Capote, Senior Vice President of Corporate Services at CAN Community Health (CAN), oversaw the event planning team hosting the 20th Anniversary CANDance revenue in the fall of 2019. The event was inspired by the hit television show "Dancing with the Stars." At the affair, affluent philanthropic community members competed for two championship titles, "Dance Champion" and "Fundraising Champion." That year was designed as the Tournament of Champions and winners from previous years returned to compete for the ultimate trophy. To add more excitement, CAN announced a new Youth Initiative. The funds raised at the 2019 CANDance revenue were intended to jump-start the program which would have provided critical outreach services in local communities.

Among the champions was Shelly Martin. She was a socialite who owned several hotels and night clubs in Siesta Key. Martin was very well- known in the area and had an extensive network of wealthy associates that could be potential donors at future fundraisers. The morning of the event, Martin approached Capote and verbally committed a pledge of $\$ 250,000$. This was the largest donation that CAN had ever received at a fundraising event. With a donation of this magnitude, Martin automatically won the "Fundraising Champion" title.

Typically, a large donation is vetted, and the donor would be asked to sign a Donation Commitment Form which served as a legally binding document that guaranteed payment (Exhibit 1). However, with all the chaos of coordinating the event, Capote did not have time to provide the form, validate commitment, verify funds, or coordinate the logistics of payment. Both parties agreed to accomplish this in the morning.

In the weeks following the event, Capote made numerous attempts to contact Martin and collect the funds. However, she was unresponsive, and he suspected she would not honor her pledge. Sadly, what Capote thought would turn out to be an incredible event turned into a donor relations nightmare and the fate of the Youth Initiative hung in the balance. Should he have pursued Martin to recover the money or considered other alternatives?

${ }^{1}$ Copyright $(0)$ 2018, Scott Breitengross, Scott Campbell, Roger Capote, Leigh Cowan, Adilah Everett-Long. This case was prepared for the purpose of class discussion, and not to illustrate the effective or ineffective handling of an administrative situation. Names and some information have been disguised. This case is published under a Creative Commons BY-NC license. Permission is granted to copy and distribute this case for non-commercial purposes, in both printed and electronic formats. 


\section{Nonprofit Organizations}

"Charitable nonprofits embody the best of America. They provide a way for people to work together for the common good, transforming shared beliefs and hopes into action. They give shape to our boldest dreams, highest ideals, and noblest causes. America's 1.3 million charitable nonprofits feed, heal, shelter, educate, inspire, enlighten, and nurture people of every age, gender, race, and socioeconomic status, from coast to coast, border to border, and beyond. They foster civic engagement and leadership, drive economic growth, and strengthen the fabric of our communities. Every single day." (National Council of Nonprofits, 2020)

The term "nonprofit" has a different meaning for many people. The term "tax exempt" and "nonprofit" are often used interchangeably. "Congress has created almost three dozen types of tax-exempt organizations in different sections of the tax code. These include Section 501(c)(4) (social welfare organizations, homeowners' associations, and volunteer fire companies), Section 501(c)(5) (includes labor unions), Section 501(c)(6) (includes chambers of commerce), and Section 501(k) (childcare organizations). Each section identifies certain conditions that must be met to be exempt from paying federal income taxes. The one common condition is not paying out profits ("no part of the organization's net earnings can ensue to the benefit of any private shareholder or individual"); hence the term, "nonprofit." Section 501(c)(3) of the tax code refers to "public charities" (also known as charitable nonprofits) and "private foundations." The tax code considers "churches and religious organizations" (which the IRS defines to include mosques, synagogues, temples, and other houses of worship) to be "public charities."(Source: What is a "Nonprofit"?, 2019)

\section{CAN Community Health (CAN)}

CAN Community Health, Inc. (CAN) was a 501.C(3) nonprofit organization. Its mission was to provide a continuum of medical, social, and education services for the health and well-being of those living with $\mathrm{HIV}$, hepatitis $\mathrm{C}$, sexually transmitted diseases, other diseases and to enhance public awareness. CAN was the 3rd largest private provider of HIV services in the nation, serving over 20,000 clients annually. Their growth was primarily facilitated through collaborations with local organizations that serve higher-risk populations. Established in Sarasota, FL, in 1991, CAN provided services in Arizona, New Jersey, Virginia, and South Carolina. Its 36 service sites offered treatment, education, and support services to persons living with HIV, Hepatitis C, and/or STDs regardless of their financial situation, insurance status, or ability to pay.

Within its service areas, CAN had walk-in clinics that served as a base for the services provided nationwide, which included an HIV rapid start mobile clinic and outreach team. The CAN mobile clinic traveled throughout their service areas and the corresponding states and provided health screenings to community members, reduced the stigma surrounding HIV testing, and initiated rapid start antiretroviral treatment for individuals who tested positive for HIV.

CAN expanded its mission by partnering with other community-based organizations. CAN partnered with 11 organizations to develop access to care that addressed the medical, behavioral, dental, and social needs of the community (Exhibit 2 and 3). Their mission to serve the HIV Community went beyond the services provided in clinics. Between 2018-2019 CAN contributed over \$3 Million for client assistance. Examples of client assistance included Housing Assistance: Rent / Mortgage Payments, Transportation: Uber Rides, Bus Passes, Therapy / Counseling, Car Repairs, Utility Bills Payments, Dental Work and Other Medical Treatments (Exhibit 4). 
In November of 2018, CAN Community Health purchased an 80\% share of Mail Meds Clinical Pharmacy and Tampa Family Pharmacy. They had three clinic Pharmacies in Jacksonville, Clearwater, and Ft Lauderdale, with plans for future expansion. The partnership allowed CAN to improve access to medications for indigent patients, implement pharmaceutical care programs, and bring clinical pharmacy services to improve patient care \& outcomes.

CAN Community Health received funds through grants from federal and state governments, donations, special events, insurance companies (for services performed), and the 340B Drug Pricing Program through in-house and contracted pharmacies. The 340B Drug Pricing Program resulted from the enactment of Public Law 102-585, the veterans' health care act of 1992. It required drug manufacturers that participated in the Medicaid program provide covered outpatient drugs to certain covered entities at a reduced price. These covered entities included safety net providers in the form hospitals and federal grantees (including HIV/AIDS providers who participated in the Ryan White and STD programs) (U.S. Health Resources \& Services Administration, n.d.). 340B covered entities provided high quality, accessible, and affordable health care to communities in underserved areas. The 340B program enabled CAN with the ability to stretch resources and provided a full continuum of care to underserved and uninsured patients, including people living with HIV/AIDS and Hepatitis C (Exhibit 5).

Ryan White HIV/AIDS Patient Care Programs: The Ryan White HIV/AIDS Patient Care Program was the most significant federal program focused exclusively on HIV/AIDS Care. CAN Community Health provided services under Part A and B. The Program funds grants to states, cities/counties, and local community-based organizations to provide care and treatment services to people living with HIV to improve health outcomes and reduce HIV transmission among hard-to-reach populations.

STD Direct \& In-Kind Programs: A CDC funded program that furthered STD prevention and control programs. CAN provided services as both Direct \& In-kind recipients.

Local \& State Funding: Medicaid Programs, Grants, Fundraisers, and Donations.

\section{Similar Organizations}

AIDS Healthcare Foundation (AHF) was established in 1987 and was headquartered in Los Angeles, California. They were a large global organization with 65,000 employees that provided care to over 1.3 million people in 45 countries. They fostered partnerships with pharmacies, thrift stores, and healthcare facilities to provide treatment, prevention, and support for people living with HIV. Their goal was to lead a mass testing initiative that would provide 1 billion tests annually (Welcome, 2020). The Los Angeles LGBT Center was established in 1969, founded by Morris Knight, offered programs and services for lesbian, gay, bisexual, and transgender people. The organization's work spanned four categories, including health, social services, housing, and leadership and advocacy (Los Angeles LGBT center, n.d.)

Although CAN Community Health operated in the United States at this time, it looks to organizations like The Elizabeth Glaser Pediatric AIDS Foundation and The International AIDS Vaccine Initiative for reference on a global scale. The Elizabeth Glaser Pediatric AIDS Foundation, founded in 1988, is a nonprofit organization dedicated to preventing pediatric HIV infection and eliminating pediatric AIDS through research, advocacy, and prevention and treatment programs. The organization works in 12 countries around the world (Elizabeth Glaser Pediatric AIDS Foundation, n.d.). The International AIDS Vaccine Initiative was a global not-for-profit, a public-private partnership working to accelerate the development of vaccines to prevent HIV infection and AIDS (International AIDS Vaccine Initiative, n.d.) 
BREITENGROSS, CAMPBELL, CAPOTE, COWAN, EVERETT-LONG

These organizations provided education, treatment, and prevention of HIV/AIDS and other STDs. Services were confidential and provided at little or no cost to the patient. Funding was obtained through donations, grants, and fundraising. (See Exhibit 6 for Competitive Analysis)

\section{The Youth Initiative}

A major differentiating factor between these two organizations and CAN was CAN Community Health's new Youth Initiative. This Youth Initiative included a safe space model of STD intervention for at-risk youth, ages 13-21. The program provided them with leadership and decision-making authority to promote sexual health testing directly to their peers. Many of the underserved youth in our communities were homeless or did not have a stable living situation and were statistically at high-risk for STDs. Lack of familial and school support, combined with a lack of comprehensive in-school sex education meant the initiative was essential for STD prevention, education, testing, and linkages to care.

Through these mentoring relationships, CAN Community Health's Youth Initiative aimed to promote resiliency and social capital among sexual and gender minority youth with multiple vulnerabilities and risk factors for adverse psychosocial and biomedical outcomes, including social marginalization, victimization, substance abuse, mental health concerns, school dropout, poverty, and persistent homelessness, which contributed substantially to elevated risk for HIV, other sexually transmitted infections, and adverse physical and mental health outcomes.

This program offered high quality mentoring relationships for sexual and gender minority youth, which were intended to provide enhanced support and promote resiliency to offset the stressors these youth encountered as a member of child welfare and/or juvenile justice systems including the additional burden of minority stress faced by sexual and gender minority youth. Having a stable, positive relationship with one or more adult role models contributed to healthy self-esteem development, confidence, and development of prosocial skills for youth in general and especially critical for vulnerable youth involved in the child welfare and juvenile justice systems.

\section{The Dilemma}

Within twenty-four hours of being crowned the "Fundraising Champion," Martin suffered a massive heart attack and was subsequently in and out of the hospital for several months. Capote respectfully took the time to let Martin recover before he attempted to collect the pledged donation. Lunch was attempted in mid-November, but she canceled due to lingering health issues. A certified letter was also sent with no reply. After not having success remedying this dilemma on his own, Capote consulted with CAN's CEO and other Executive Leaders. They agreed the best course of action was to remain in contact with Martin during her recovery process and give her time to enjoy the holidays with friends and family before resuming efforts to obtain the money.

Capote resumed efforts to reach out to Martin after the new year but received no response. Communication attempts continued for several weeks; Capote reached out to Martin's spouse, board members, community members, and friends and with no luck. Martin had seemingly fallen off the face of the earth until January 26th, when she resurfaced on social media, seeming joyful, full of energy and all smiles in local society photos at yet another charity event.

Capote was stuck with a tough decision on how to proceed. These charity events were the lifeblood of their nonprofit organization. Donations from wealthy and influential people often prompted others to donate and could be the difference between a successful and non-successful fundraiser. Generous 
contributions like the one promised by Martin were often earmarked for specific programs; in this case, it was the Youth Initiative. Losing a donation of this magnitude would hurt the mission of CAN and its Youth Initiative. They would not have the funding needed to provide the intended assistance promised to their clients. This would have been embarrassing for both Capote and the organization.

Although discouraged, Capote held out hope that Martin would make good on her pledge. He was undoubtedly sympathetic to the medical issues she had faced and did not feel it was appropriate to push the issue while she was in recovery. It was possible that with the medical hardship and three month time span between the fundraiser, Martin merely forgot and needed to be reminded. In all the communication with Martin's associates, it was clear that they were not aware of the pledge. Perhaps Capote should give her the benefit of the doubt and not just assume she was no longer honoring the commitment of funds. Could this have been a simple miscommunication that could be cleared up? Martin's appearance at another fundraiser suggested there was not a financial reason she had not honored her donation pledge. Perhaps Capote should have continued to reach out to her until he was able to get concrete answers. Abandoning such a large donation over a simple misunderstanding would be a massive error. Capote wanted to make every reasonable attempt to collect before he gave up and was forced to find other alternatives for the lost revenue.

There had to be another consideration. As with many things, perception could create reality. If Capote continued to pursue Martin, he could be perceived negatively by pestering a very wealthy, powerful, and influential member of the community. Would Martin take offense and influence other donors into stepping away from their donations as well? Would CAN receive a bad reputation and be condemned for the tactics they used to collect donations? Perhaps worst of all, if CAN was perceived to be unsympathetic to an influential donor during a medical crisis, would it become a stain on the fundraising arm of CAN that would be hard to recover from?

Capote knew he had to consider his plan of action carefully. As he saw it, there were a few options, each having its own set of pros and cons.

\section{The Decision}

After much deliberation with the Board of Trustees, Event Chairs, and the CAN Executive team; Capote and the CEO formulated these four (4) courses of action:

1. Do Nothing - Simply stated. Write off the amount that was promised and assume the loss.

2. Show Me the Money - Continue to pursue Martin for the funds promised. Offer a payment plan option if needed and take legal action if the issue could not be resolved.

3. Expose the Donor - Call a press conference with local media and society photographers to strip her of the "Fundraising Champion" title and expose Martin as a fraud. Public scrutiny ma prompt Martin to pay the money in order to salvage her reputation.

4. Take lemons and make lemonade - Organize another charity event with all the participants of CANDance and recognize the rightful "Fundraising Champion" with a trophy. Positive publicity could generate more donations for the Youth Initiative. 


\section{The Reflection}

There was a lot to process. CAN had been a part of this community for over 30 years. Capote had been a member of this community for over 15 years. He did not want the reputation of the organization to be diminished by bad publicity. The funds promised by Shelly Martin would have greatly benefited the Youth Initiative, but he wasn't sure it was worth the risk of damaging CAN's reputation. 


\section{References}

AIDS Healthcare Foundation. (n.d.). Welcome. Retrieved April 4, 2020, from https://www.ahf.org/

Elizabeth Glaser Pediatric AIDS Foundation. Our history. (n.d.). Retrieved April 4, 2020, from

https://www.pedaids.org/about/

International AIDS Vaccine Initiative. (n.d.) Translating scientific discoveries. Retrieved April 4, 2020, from https://www.iavi.org/

Los Angeles LGBT center. (n.d.). About the center. Retrieved April 4, 2020, from

https://lalgbtcenter.org/about-the-center

National Council of Nonprofits. (n.d.) What is a nonprofit. Retrieved April 3, 2020, from

https://www.councilofnonprofits.org/what-is-a-nonprofit

U.S. Health Resources \& Services Administration. (n.d.) Grants. Retrieved from http://www.hrsa.gov/ 


\section{Biographies}

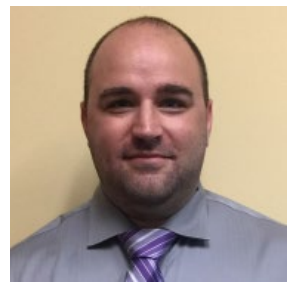

Scott Breitengross makes it his business to leave a mark on everything he touches. He is president of Premium Precision Products, a company that specializes in engraveable products. With 18 years of work experience, the past 12 of which have been in leadership roles, he supervises a staff of 12 employees. He has managerial duties over his staff and teams of independent contractors who produce the company's niche product for resale. He is responsible for IT services, marketing, accounting and other administrative tasks. His goal in enrolling in the Executive MBA program is to increase his business acumen, build a business and leadership network with other professionals and take his business to the next level. He has served in the U.S. Navy, where he was an engineering officer and weapons officer aboard the USS Missouri. He also served as a department head in the Submarine Learning Center, where he earned a Navy Commendation Medal. Breitengross received a bachelor's degree in aerospace and aeronautics engineering from Purdue University in Indiana.

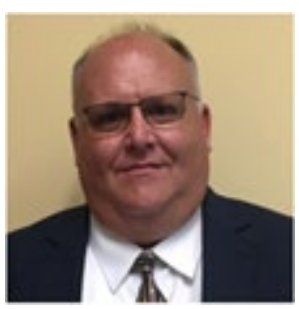

Scott Campbell started his career in commercial construction as a field engineer after graduating from the University of Florida with a bachelor's degree in building construction. Choosing to work in construction came naturally to him, as his father worked in high rise construction. By working in field roles as well as office roles, Campbell acquired a diverse skillset to perform operations efficiently and effectively. He enjoys working with collaborative and creative people, using teamwork to come together and achieve challenging goals. Campbell is passionate about helping others and improving the communities we live in. He has participated on the board for Habitat for Humanity in Hillsborough County for five years and regularly enjoys volunteering. He has also participated on the board of ABC Contractors for the Gulf Coast Chapter, working to help provide training for our future trade workers. In his spare time, Campbell enjoys being on the water, whether that be boating or fishing. He currently resides in downtown St. Petersburg with his wife and son.

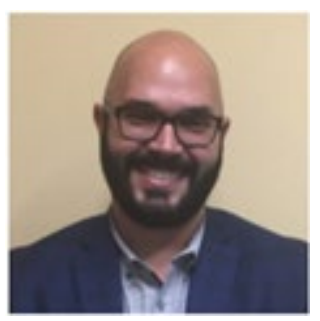

Rogelio Capote is the Senior Vice President of Corporate Services for CAN Community Health. He is responsible for leading a team to cultivate major gifts and oversees the planning and execution of all marketing and advertising initiatives. He came from being senior director of special projects at the Marie Selby Botanical Gardens. In his current position, Capote oversees marketing, strategic outreach, guides fundraising efforts and develops community programs that advance the organization's mission and brand. CAN Community Health owns and operates 34 non-profit medical clinics throughout the southeastern United States and Puerto Rico. Capote received a bachelor's degree in parks, recreation and tourism management from the University of Florida.

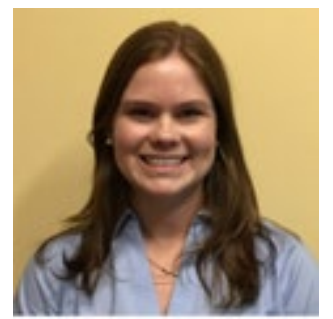

Leigh Cowan is the State and Local Disaster Response and Recovery Manager for IEM, Inc, a national Emergency Management consulting firm. In her prior role, she was the Logistics Director for Century Ambulance Service in Jacksonville, FL, where she oversaw the Dispatch, Safety, Supply, Scheduling, and Information Technology departments. Earlier in her public safety career, her duties as Program Administrator with Pasco County Public Safety required her to oversee the budget and other managerial duties for Pasco County's Emergency Management, Fire Rescue, Misdemeanor Probation, and Dispatch departments. Cowan received 
bachelor's degrees in environmental studies and applied geography from the University of North Carolina Wilmington, and a master's degree in Florida studies from USF St. Petersburg.

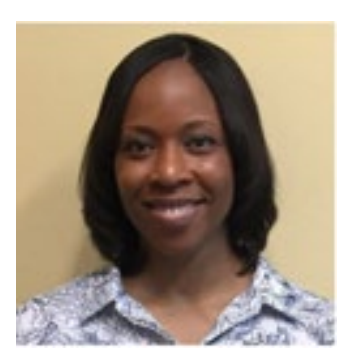

Adilah Everett-Long retired from the U.S. Air Force and is looking forward to the next chapter in her life. Previously, she was the senior manager of dental support at MacDill Air Force Base in Tampa, where she supported the dental clinic staff so they could provide high-quality care to their patients. She oversaw six departments and 23 employees and was responsible for all non-clinical operations in a clinic that has over 50 employees providing service to 12,000 active-duty service members. She has 20 years of work experience, 15 of which has been in managerial positions, and she has been in her current job for the past four years. Everett-Long received a bachelor's degree in health-care administration from Ashford University in California. 


\section{Exhibit 1: Example of a Donation Agreement}

\section{LETTER OF INTENT TO DONATE EXAMPLE}

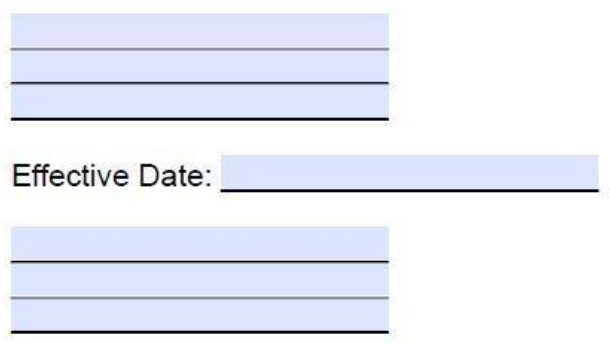

\section{RE: Donation to Qualified Organization}

This donation letter of intent (the "Letter of Intent") represents the basic terms for an agreement that shall be considered $\square$ binding $\square$ non-binding. After this Letter of Intent has been made, a formal agreement may be constructed to the benefit of the Parties involved.

I. The Donor: (the "Donor").

II. The Donee: (the "Donee").

III. The Donation: Choose One (1)

One-time Monetary Donation: The Donor wishes to make a one-time monetary donation to the Donee in the amount of $\$$

Monthly Pledge: The Donor wishes to make a monthly donation of \$ Donee beginning and $\square$ ending to the total donation of $\$$ OR $\square$ ongoing until further notice.

Annual Pledge: The Donor wishes to make an annual donation of $\$$ Donee each year for years, beginning $\$$

Other: The Donor wishes to donate the following to the Donee:

IV. Donation Designation: The above-described donation should be used for the following purpose(s):

V. Alterations to Donation Designation: The Donee may need to alter the donation designation to ensure that current priorities are met. Should this be required, the Donee will respect the initial intent of this letter as closely as possible. 


\section{Donation Recognition: Choose One (1)}

The Donor agrees to be recognized for the donation under the following name(s):

The Donor wishes to remain anonymous.

VII. Method of Payment: (Monetary Donations Only)

Cash or Check (If paying by check, make check payable to )

Credit Card - Card Information:

Automatic Withdrawal (attach void check)

The Donor authorizes the Donee to withdrawal funds from his/her financial institution account.

Donor's Signature Date

VIII. Organization Type: The Donee is an organization that is: Choose One (1)

Classified as a 501 (c)(3) non-profit organization by the standards of the Internal Revenue Service (IRS). Therefore, the donation may be tax-deductible to the extent allowed by law.

Not classified as a 501 (c)(3) non-profit organization by the standards of the Internal Revenue Service (IRS).

IX. Currency: All mentions of currency or the usage of the "\$" icon shall be known as referring to the US Dollar.

X. Governing Law: This Letter of Intent shall be governed under the laws of the State of

$\mathrm{XI}$. Acceptance: If you are agreeable to the aforementioned terms, please sign and return a duplicate copy of this Letter of Intent by no later than

\section{DONOR}

Donor's Signature Date

Print Name

\section{DONEE}

Authorized Signature Date

Print Name 


\section{Partnerships}

CAN has partnered with 11 organizations to expand access to care that address medical, behavioral, dental, and social needs of the community.
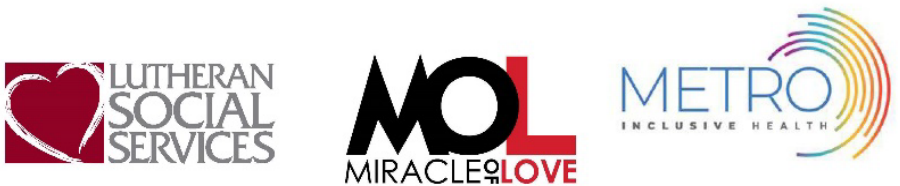

Debres $\operatorname{Simith} 2$

ij: pridelines

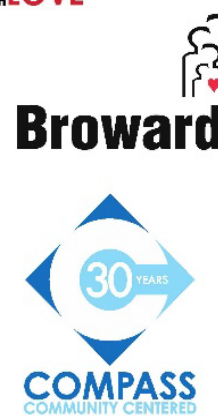

डी House

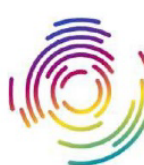
LGBT LIFE CENTER

PUEBLO FAMILY PHYSICIANS
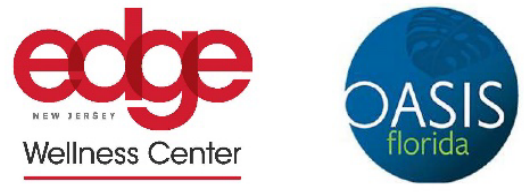

Copyight@2020 CANCOMMUNITYHEALTH 


\section{Locations}

Headquarters in Sarasota FL, CAN operates 6 Owned Clinics, 18 Partnered Clinics with other organizations, and 10 Contracted Clinics with independent practices, In Florida, South Carolina, Virginia, New Jersey, Arizona.

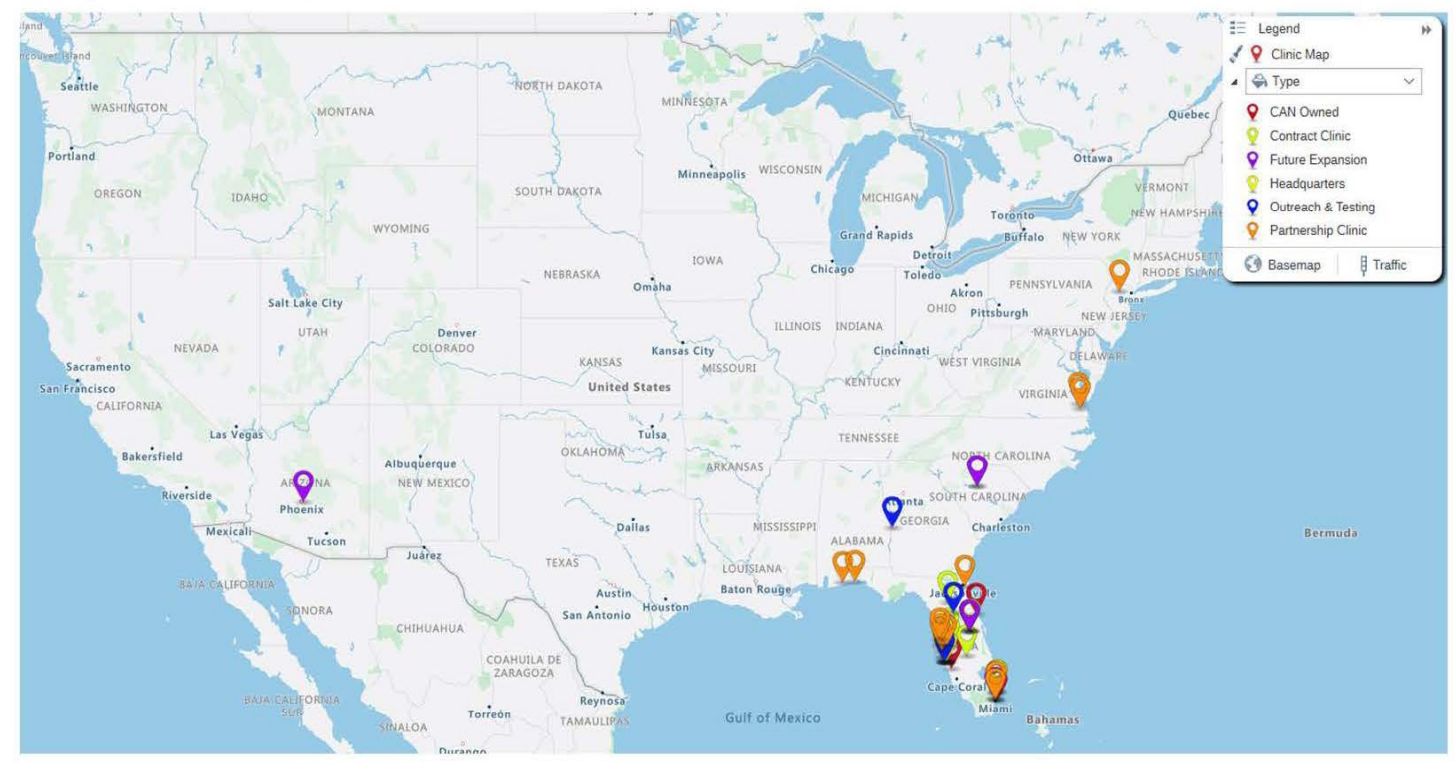

Copyright (C) 2020 CAN COMMUNITY HEALTH 


\section{Client Assistance since July 2016 CX̂N $\mathbf{N}_{\text {HeALIH }}^{\text {comuriy }}$}

CAN's dedication to client care has continued to grow

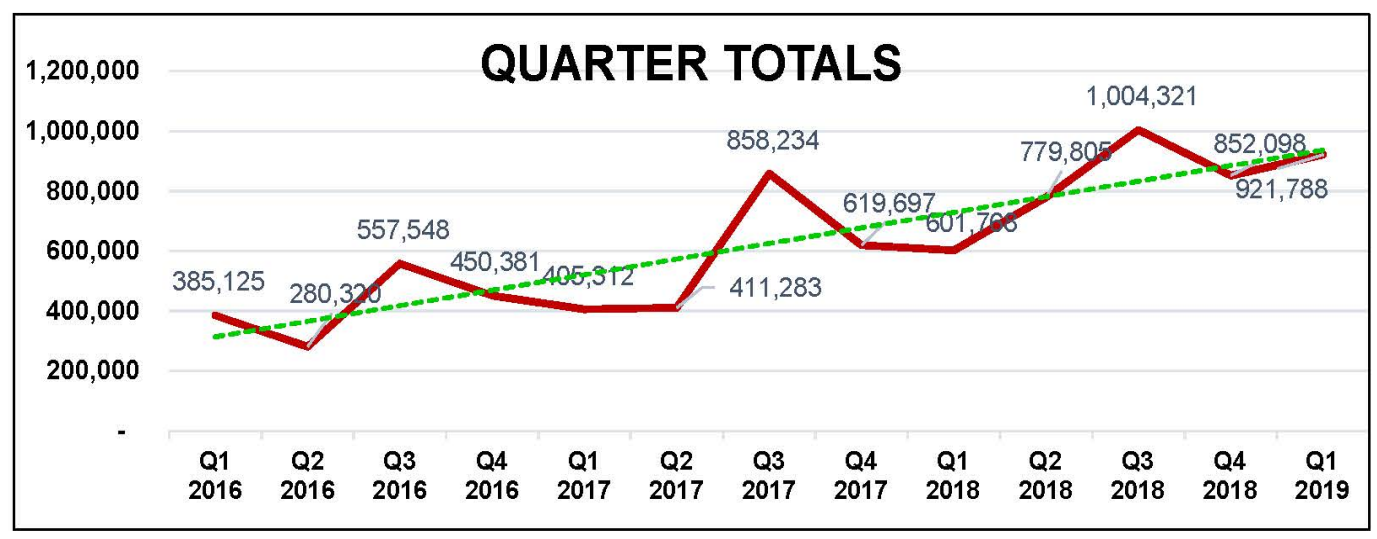

Copyright $\odot 2020$ CAN COMMUNITY HEALTH 


\section{B How Does it Work?}

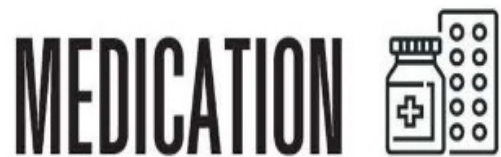

Drug manufacturers develop effective outpatient medications and make them available to qualified healthcare organizations such as hospital, clinics and pharmacies.

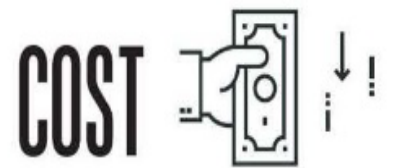

12

Only healthcare organizations who meet strict regulatory requirements are able to qualify as a $340 \mathrm{~b}$ healthcare organization and as such are able to purchase medications through a reduced cost pay program.

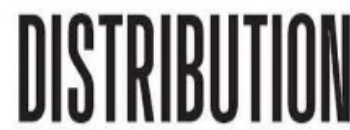

1

CAN provides medications to our patients and to our pharmacies through our extensive pharmacy network. (both owned and contracted pharmacies)

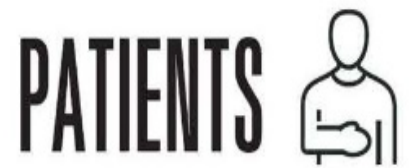

Low income or patients without insurance will receive these medications at little or no cost. Insured patients pay their normal copay and their insurance company pays CAN.
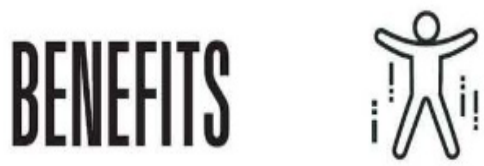

The savings generated by CAN's qualification as a $340 \mathrm{~b}$ healthcare organization is what enables us to further our mission to provide healthcare, pharmacy programs and support services to our patients. It also allows us to open clinics in areas that have need. 


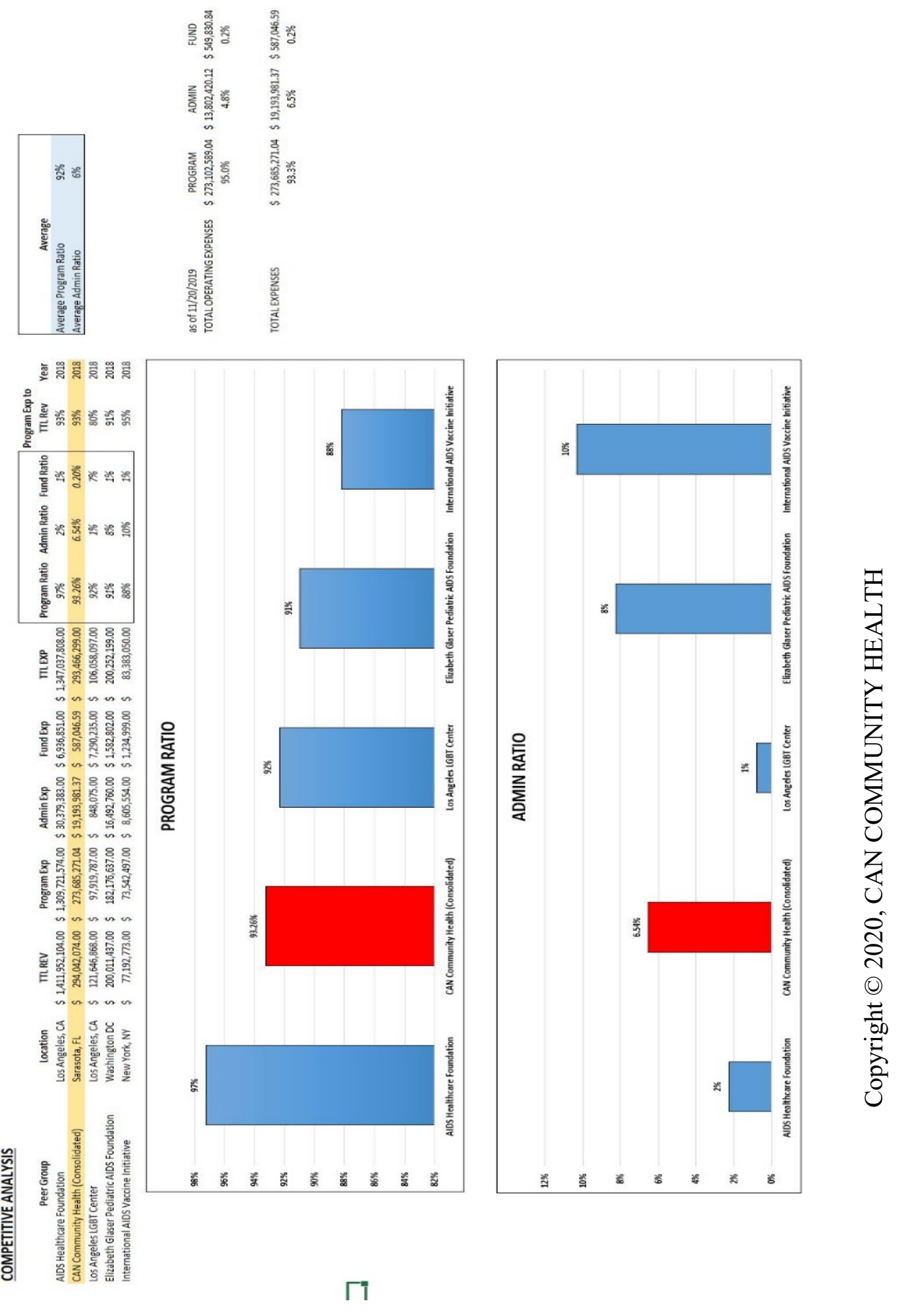

